\title{
Multinational company product's influence on expenditure pattern
}

Received : 20.10.2015; Revised : 16.02.2016; Accepted : 17.03.2016

\begin{abstract}
Today in this era of globalization the Indian market has gone through a dramatic change. The consumption patterns of Indians are slowly moving towards unsustainable levels, while resources as domestic savings are depleting at an alarming rate. To investigate the influence of multinational company products on expenditure pattern of urban households. The study was exploratory in nature. The locale of the study was the twin cities of Hyderabad and Secunderabad of the State of Andhra Pradesh. The total sample sizes of 300 were selected by using stratified random sampling techniques. 100 each belonging to three income categories viz., HIG, MIG and LIG. An interview schedule was designed for the purpose of collection of data from the respondents. For gathering information the following five scales were developed. Consumer product susceptibility and innovativeness scale (CPSIS), The consumer ethnocentrism scale (CES), the goal congruency scale (GCS), product influence on attitude scale (PIAS), the enculturation - acculturation scale (EAS). When the consumers were highly susceptible innovative, ethnocentric, then the expenditure for MNCPS were high. Also when the MNCPs were highly goal congruent, MNCP had good attributes, MNC concern for customers satisfaction were high than in these cases expenditure for MNCP was high.
\end{abstract}

KEY WORDS : Multinational company products, Enculturation, Acculturation, Innovativeness, Susceptibility, Ethnocentrism

How to cite this paper : Pandey, Jyoti (2016). Multinational company product's influence on expenditure pattern. Internat. J. Com. \& Bus. Manage, 9(1): 44-48. 